\title{
Glottic Laryngeal Tumor with Subglottic
} Extension

National Cancer Institute

\section{Source}

National Cancer Institute. Glottic Laryngeal T umor with Subglottic Extension. NCI

Thesaurus. Code C161004.

A finding of glottic involvement from a laryngeal tumor with extension of the tumor into the subglottis. 